\title{
INTRODUCTION
}

\author{
Jordan Mechner
}

$\mathbf{T}$

HE day I met Rassouli, he shared a childhood memory of afternoons spent with his uncle in a teahouse in Isfahan, a historic city in central Iran, listening spellbound to adventure tales spun by a storyteller in the ancient Persian oral tradition that had produced the Thousand and One Nights. The stories that had most enthralled him as a boy, he told me, featured as their main hero an ayyar named Samak-a member of a class of warriors in Persia with deep roots going back thousands of years.

I grew up in New York in the I970s; my exposure to Persian lore had been second- or third-hand, through illustrated children's editions of the Nights, Hollywood derivatives like the 1940 Technicolor Thief of Baghdad (starring Conrad Veidt as a scheming vizier named Jaffar), Mad magazine, and Ali Baba Bunny. (Fourthhand might be more like it.) The power of those ancient tales and archetypes nonetheless came through vividly enough to inspire me to create, in my twenties, a video game called Prince of Persia.

Over the next two decades, researching and writing Prince of Persia sequels, reboots, and adaptations for increasingly high-resolution platforms (from the $280 \mathrm{x}$ I92 pixel Apple II computer screen to a $4 \mathrm{~K}$ Disney live-action movie starring Ben Kingsley as 
a scheming vizier named Nizam), I'd gained an amateur's familiarity with the thousand-year-old source material, especially the Nights and Ferdowsi's Shahnameh. But in all my reading, I'd never heard of ayyars. Rassouli made them sound like a kind of Persian Robin Hood or ronin. I was fascinated.

Rassouli explained that although ayyars came from a lower social class, their code of brotherhood was noble, including loyalty, honor, self-sacrifice, and never turning away the hand that reaches out for help. Samak is not just a brute-force warrior but a trickster who foresees dangers and problems before anyone else and prevents them through decisive and surprising action. $\mathrm{He}$ embodies a heroic ethic that has resonated in stories for every generation, and one that the world needs now as much as ever.

Rassouli pulled a volume from his shelf and opened to a page at random. As he began to read, translating on the fly from archaic Persian into English, chills ran down my spine. Here was an adventure set in ancient Persia involving a beautiful princess, a treacherous vizier, kings, armies, witches, and an agile hero who scaled walls and snuck into palaces. More than just an entertaining tale, it offered vivid glimpses of the everyday life of the era, with details I hadn't been able to find anywhere else. It was the source material Prince of Persia had always wanted but never had.

The friend who introduced me to Rassouli had described him as an Iranian-born painter and writer, passionate about Persian history and culture, who had translated the poetry of Rumi, Hafiz, Attar, Omar Khayyam, and others. I'd come to him hoping to enrich and deepen my understanding of Prince of Persia's world and mythology as I worked with a team of designers and artists preparing to pitch a new take on the franchise.

I told Rassouli that I absolutely had to get my hands on an English edition of Samak-e Ayyar. He explained that there wasn't one; the original work was unknown outside of Iran and even to 
most Iranians. It was a small miracle that it had survived in written form at all. The Mongol invasions of the thirteenth century had burned Persia's libraries and destroyed a vast swath of its literature. The tales of Samak, as part of Persia's oral tradition, were believed lost until the I96os, when a scholar visiting the Bodleian Library in Oxford, England, made an unexpected discovery. An old Persian manuscript that had been preserved for its color illustrations - the oldest in the museum's collection-was in fact Samak-e Ayyar, transcribed in the twelfth century from a still older manuscript by one or more unknown scribes, recording the narration of a master storyteller from Shiraz.

Dr. Parviz Natel Khanlari, Iranian poet and professor of language and literature, reconstituted the archaic Persian text from disparate source materials (including a missing volume that turned up later in a sixteenth-century Turkish translation in the British Museum). Thus Samak-e Ayyar was published for the first time in a limited edition in Tehran in 1969. It promptly went out of print.

It seemed-and still seems-incredible to me that popular modern-language editions of Samak haven't been published around the world, as have the better-known (but not more deserving) tales of Aladdin, Sinbad, Ali Baba, and the Thousand and One Nights. By the time Rassouli and I said goodbye at the end of our first evening together, we had pledged to fill that gap. It felt like destiny had entrusted us with a mission. Rassouli had never played a video game, much less expected to join a team that was creating one; I had never expected to adapt a twelve-hundred-page archaic Persian manuscript. But thanks to Samak the trickster and the unlikely chain of events that led me to Rassouli's studio, it was obvious that this was what we needed to do.

How Rassouli collected all six out-of-print volumes of Samake Ayyar is an adventure tale in itself. He enlisted his brother to take a road trip from Isfahan to an antiquarian bookstore in 
Nishapur, and then a plane flight from Tehran to Dubai to mail the books to Los Angeles (package shipments from Iran to the United States having been suspended due to the political situation at the time).

Ironically, the video game project that had brought us together ended up being cancelled in preproduction. (That's a tale to be told another time. The workings of the game industry can be as arcane as those of Abbasid kings and viziers.) By then, Rassouli was deep into translating the Persian manuscript with no intention of stopping. When an ayyar accepts a mission, you can be sure he will complete it, even if the promised reward is withdrawn or circumstances take an unfavorable turn. Video game or no, Samak had inspired our commitment and loyalty, as he does for Sorkhvard, Ruzafzun, Atashak, and other characters in the book.

\section{ABOUT THE TRANSLATION}

Our priority was to create an entertaining, readable, yet faithful and complete modern-language version of Samak-e Ayyar to make this great work accessible for the first time to a global audience.

In general, we tried to use plain language and avoid unfamiliar terms. The word ayyar is an exception: the concept is so central to the story that we had to keep it. We dare to hope that ayyar may one day enter the popular lexicon, like samurai and ronin, terms that were also once unknown in the West.

For other Persian words with no direct Western equivalent, we wrote around them. Rather than try to define javanmardi, for example, we sought to translate its essence using phrases like brotherhood, honor, loyalty, altruism, and noble conduct, all of which the term connotes. 
Because I read no Persian, Rassouli's first step was to render a raw literal English translation of Khanlari's work. Eliminating materials extraneous to the story flow-poems inserted later, requests for prayers for the scribes at the beginnings and ends of dictation sessions, ritually repeated rhymes that Persian storytellers used (and still do) while waiting for the audience to gather and to collect money at the ends of their performances- - he divided the story roughly into chapters, which he handed on to me.

As Samak unspooled before my eyes, I became addicted, eagerly awaiting Rassouli's weekly emails to find out what happened next. The deft interweaving of a large, diverse cast of characters, with parallel action in multiple locations, alternating visceral combat and epic battle scenes with humor and intimate moments, was like an HBO series. Its world felt both archaic and startlingly modern. Female ayyars are brave, deadly, and vulnerable; princes and warriors drink wine in army tents on the eve of battle; nobles and commoners struggle to reconcile their hearts with duty to leaders who unleash a devastating, avoidable civil war. The triangle of friendship, loyalty, sexual attraction, envy, and gender-role frustration that binds Samak, Sorkhvard, and Ruzafzun, to take one example, felt like it could have been written yesterday rather than in the ninth century.

That said, creating a unified narrative from Khanlari's assemblage posed a challenge. Samak-e Ayyar was never a literary work by an author like Ferdowsi's Shahnameh but a folk tale transcribed from a storyteller's live performances. (The storyteller himself may have been illiterate.) Even if the task weren't complicated by gaps, missing pages, inconsistencies among recopied sections from different historical periods, and changes in narrator, the narrative itself is sometimes self-contradictory. A traveler makes a journey in one day that is described elsewhere as taking a month. A person on foot arrives before a rider on horseback. A character 
established as being in a particular place disappears from the action for a stretch, as if the storyteller had forgotten he was there. Two characters meet for the first time, unaware that they already shared an escapade several chapters earlier. The pacing is uneven: the death of a minor character is described in detail, while one central to the story is dispatched abruptly with no fanfare.

Such discrepancies are understandable in a complex story recited by a storyteller accustomed to improvising and adapting his memorized material to suit the occasion. We can assume he was never given the opportunity to go back and edit the transcription as a whole. It would be beyond remarkable if the manuscript's thousand-odd pages fit together perfectly.

In a printed book, where the reader can flip back and compare one passage with another fifty pages earlier, inconsistencies are more distracting than in a story heard aloud. An unedited manuscript makes for a bumpy read. As much as Rassouli and I wanted to be faithful to the original, it became clear that a strict literal translation would be a book few readers would have the patience to finish. Some dramatic license was required.

For example, considering the vizier Mehran's importance in part I, the way Samak deals with him and Surkhkafar in chapters 33-37 of part II seemed too desultory, dependent on coincidence and illogical behavior. I tweaked the original action beats to achieve the same end result in a way that felt more plausible to me and consistent with the setup, characters, and world established by the storyteller. Elsewhere, I took smaller liberties of adding dialogue, description, or action to flesh out moments that wanted it, or I streamlined narration that felt tedious or repetitive. Such changes can become a slippery slope. I hope the reader will find ours judicious and in keeping with both the spirit and the detail of the original.

Given Samak's large cast of characters and diverse world map, our approach to names deserves a note. We retained Persian 
names of most places and characters, occasionally translating them (Stone Alley, Twelve Canyons) or parts of them (Falaki Fortress, Dabur the Demon Slayer). Our guiding intention was to make it as painless as possible for readers to understand the action.

In the story, the prince of Persia journeys from his father's capital city, Halab, across a desert to a remote- but still Persianmountainous region where the kings of rival city-states Chin and Machin vie for power, drawing tribal leaders from surrounding territories into their ever-expanding war. Rassouli and I interpreted names like Halab, Chin, and Machin (which means "beyond Chin") as evocative of a timeless storyteller's realm rather than literal history or geography. We felt that to seek modern English equivalents, encouraging the reader to identify them with cities or nations whose coordinates can be found today on Google Maps, would be misleading.

The tale of Samak was already old when it was written down in the twelfth (or ninth?) century. Many character names evoke Persian archetypes and myths that date from pre-Islamic times. Mahpari means "moon fairy"; Khorshid Shah means "sun king." These too we left untranslated.

The one indisputably identifiable place is the ancient land in which Samak's storytellers and audience lived-Persia, whose culture and proud allure have endured for thousands of years, from long before this tale was put to paper until our present day.

Here is the first of five volumes of Samak the Ayyar, translated and adapted by Rassouli and me. We hope you enjoy it . . . and that these pages open a window into an enchanted world of princes and ayyars, intrigue, romance, and adventure, shaped by the collective genius of generations of Persian storytellers. 
